\title{
Association between physical function and the load pattern during stepping-up motion in community-dwelling elderly women
}

\section{$\operatorname{AUTHOR}(S):$}

Araki, Kojiro; Ikezoe, Tome; Malinowska, Katarzyna; Masaki, Mitsuhiro; Okita, Yusuke; Fukumoto, Yoshihiro; Kimura, Misaka; ... Kita, Kiyoshi; Tsuboyama, Tadao; Ichihashi, Noriaki

\section{CITATION:}

Araki, Kojiro ... [et al]. Association between physical function and the load pattern during stepping-up motion in community-dwelling elderly women. Archives of gerontology and geriatrics 2016, 66: 205-210

\section{ISSUE DATE:}

2016-09

URL:

http://hdl.handle.net/2433/243857

\section{RIGHT:}

(C) 2016. This manuscript version is made available under the CC-BY-NC-ND 4.0 license http://creativecommons.org/licenses/by-nc-nd/4.0/:; This is not the published version. Please cite only the published version.; この論文は出版社版でありません。引用の際には 出版社版をご確認ご利用ください。 
Association between physical function and the load pattern during stepping-up motion in communitydwelling elderly women

Short title: Stepping-up loading pattern and physical function in elderly

Kojiro Araki $^{\text {a* }}$, Tome Ikezoe ${ }^{\text {a }}$, Katarzyna Malinowska ${ }^{\text {a }}$, Mitsuhiro Masaki ${ }^{\text {a, }}$ Yusuke Okita ${ }^{\text {a }}$ Yoshihiro Fukumoto a,b, Misaka Kimura c, Yuya Watanabe c , Kiyoshi Kita ${ }^{\text {d }}$, Tadao Tsuboyama ${ }^{\text {a }, N o r i a k i ~ I c h i h a s h i ~}{ }^{\text {a }}$

a Human Health Sciences, Graduate School of Medicine, Kyoto University, 53 Shogoin

Kawaramachi , Sakyo-ku, Kyoto 606-8507, Japan.

b Faculty of Rehabilitation, KobeGakuin University, Ikawadani-cho Arise 518, Nishi-ku, Kobe,

Hyogo, 651-2113, Japan

c Department of Health and Sports Science, Faculty of Health and Medicine Science, KyotoGakuen

University, Nanjoootani 1-1 Sogabe-cho, Kameoka, Kyoto, 621-8555, Japan

d Kita Orthopedic Clinic, 1-165-5 Asagiriminami-cho, Akashi, Hyogo, 673-0863, Japan 
* Corresponding author. Human Health Sciences, Graduate School of Medicine, Kyoto University,

53 Kawahara-cho, Shogoin, Sakyo-ku, Kyoto 606-8507, Japan.

Tel: +81-75-751-3951. E-mail address: ptaraki@gmail.com 


\section{Abstract}

Objective: Stepping-up motion is challenging task for elderly people in daily life. The present study investigated the relationship between the load pattern during stepping-up motion at maximum speed and physical function in elderly women.

Methods: The subjects comprised 109 community-dwelling elderly women (age 72.5 \pm 5.3 years) . The load pattern (maximum load, rate of load production, and stepping-up time) during ascending a $30 \mathrm{~cm}$ step at maximum speed was measured, using a step up platform that measures the load at the lower and upper level. Physical function, including hip and knee extensor strength and performance on the vertical jump test, one-legged stance test, timed “Up \& Go”" (TUG) test, and stepping test were measured.

Results: Pearson's correlation analysis showed that stepping-up time was correlated with the maximum load at the lower level $(r=-0.51)$, but not with the maximum load at the upper level. A multiple regression analysis showed that hip extensor strength and performance on the vertical jump, TUG, and stepping tests were significant determinants of the load pattern during stepping-up motion in the elderly women.

Conclusions: Our study revealed that rapid stepping-up ability was more closely related to the maximum load during push-off at the lower level rather than that during weight loading on the upper 
level, and that the load pattern during stepping-up motion in elderly women was associated with various physical functions such as the hip extensor strength, leg muscle power, dynamic balance function, and agility.

Keywords:

stepping-up motion; load pattern; elderly people; physical function

Highlights:

\# Stepping-up time at maximum speed was correlated with the maximum load at the lower level during steppingup motion.

\# There was no significant relationship between the maximum load at the upper level and stepping-up time.

\# The stepping-up loading pattern in elderly women was related with various physical functions. 


\section{Introduction}

Elderly people often require assistance in performing activities of daily living(Gill \& Kurland, 2003; Hortobagyi,

Mizelle, Beam, \& DeVita, 2003; Startzell, Owens, Mulfinger, \& Cavanagh, 2000). Difficulty in stair ambulation is a serious problem among elderly people because it requires greater knee joint moments or relatively greater muscle effort as compared with walking or rising from a chair(Hortobagyi et al., 2003; Startzell et al., 2000).

Many functional assessment indices measure stair ambulation ability; however, they tend to lack validity(van Iersel, Olde Rikkert, \& Mulley, 2003). Furthermore, large, expensive, and specialized equipment is required for detailed kinetic and kinematic analysis during stair ambulation using a 3D motion analysis system(Novak \& Brouwer, 2011; Novak, Li, Yang, \& Brouwer, 2011; Samuel, Rowe, Hood, \& Nicol, 2011). As a simple assessment of the stair ambulation ability, the self-reported difficulty in climbing stairs, stair ambulation time, and maximum step height that a participant can ascend are often measured(Bean, Kiely, LaRose, Alian, \& Frontera, 2007; Nyberg et al., 2011; Oh-Park, Wang, \& Verghese, 2011; Verghese, Wang, Xue, \& Holtzer, 2008). However, self-reported difficulty in climbing stairs is not an objective assessment, stairs are needed for the measurement of stair ambulation time, and several steps are needed to measure the maximum step height. Thus, there is no simple, reliable, and objective assessment of stair ambulation capacity in elderly people.

Certain components of stair ambulation can be analyzed by measuring the vertical ground reaction force (VGRF)(Larsen, Puggaard, Hamalainen, \& Aagaard, 2008; Stacoff, Diezi, Luder, Stussi, \& Kramers-de Quervain, 
2005; Stüssi \& Debrunner, 1980), which can be achieved objectively and easily as compared to using a 3D motion analysis system. The VGRF during stair ascent shows a bimodal curve in which the first peak represents the magnitude of weight support and second represents the magnitude of push-off(Stacoff et al., 2005). Both VGRF peaks during stair ascent(Stacoff et al., 2005) and loading slope (from touch down to weight loading) on the upper level(Michel-Pellegrino, Hewson, Hogrel, \& Duchene, 2008; Stacoff et al., 2005) decrease with age(Stacoff et al., 2005) Further, the difference in the rate of increase in the first peak of the VGRF between young adults and elderly people becomes increasingly greater during stair ascent at maximum speed, compared to that at a comfortable speed(Larsen et al., 2008). Regarding the reliability of the VGRF during stair ambulation, that during stair descent is less reliable compared to the reliability during stair ascent(Stacoff et al., 2005).

Previous studies examined the VGRF during the "step-up-and-over test,” which measures the motion of steppingup and over a box at maximum speed, in patients with anterior cruciate ligament (ACL) deficiency(Lin, Hsu, Chang, Chiou, \& Lu, 2010; Mattacola, Jacobs, Rund, \& Johnson, 2004) and total knee arthroplasty(Pozzi, Snyder-Mackler, \& Zeni, J., 2015). The lift up index (that is, the maximum VGRF during stepping-up motion), which indicated upward propulsion, was significantly lower in the ACL deficiency group than in the healthy group(Mattacola et al., 2004). This result suggests that the VGRF during stepping-up motion at maximum speed using one step reflects the support function of the lower extremities. Thus, the VGRF during stepping-up motion at maximum speed could be considered as an accurate indicator of stepping-up capacity in elderly people. 
However, to our knowledge, no investigators have measured the maximum load during push-off at the lower level or that during weight loading on the upper level while stepping-up one step, thus examining the maximum loads at the upper and lower levels, respectively. Therefore, the relationship of stepping-up ability among elderly people to the maximum load during weight loading on the upper level or during push-off at the lower level is unclear. Moreover, no studies have investigated the association between the load pattern during stepping-up motion and the multidimensional factors involved in physical function in elderly people.

Accordingly, we examined the load pattern (maximum load, rate of load production, and stepping-up time) during stepping-up motion at maximum speed by using a portable step-up platform that can measure the load pattern easily and quickly. The purpose of this study was to examine the correlation between stepping-up time as an indicator of rapid stepping-up ability and maximum loads at upper and lower levels during stepping-up motion, and to investigate the relationship between the multidimensional physical function and load pattern during stepping-up motion among elderly people. Identifying load patterns of stepping-up or physical function affecting rapid steppingup motion can facilitate tailoring of interventions targeted at improving the stepping-up ability in elderly people.

\section{Participants and Methods}

\subsection{Participants}

The participants comprised of 109 community-dwelling elderly women (age 72.5 \pm 5.3 years; height $152.2 \pm 5.4 \mathrm{~cm}$; 
weight $49.5 \pm 6.3 \mathrm{~kg}$ ). Participants with physical dysfunctions that may influence the outcome measures, such as severe musculoskeletal (e.g., advanced osteoarthritis) or neurological impairments (e.g., hemiplegia), were excluded.

The elderly participants were able to ambulate independently and did not demonstrate cognitive impairment.

All participants were informed about the study procedures and they provided written informed consent before participating. The study protocol was approved by the Kyoto University’s Graduate School of Medicine Ethics Committee.

2.2 Measurements of load pattern during stepping-up motion

The load patterns during stepping-up motion were measured using a step up platform (Kyoritsu Denshi Kogyo, Japan). The step up platform (step height $30 \mathrm{~cm}$, tread depth $35 \mathrm{~cm}$, and width $70 \mathrm{~cm}$ ), consists of 4 electronic weight scales mounted onto the upper and lower level (Fig 1). The load during stepping-up motion on both the upper and lower levels was recorded on a computer (VAIO, Sony, Japan) with sampling rates of 100Hz. 


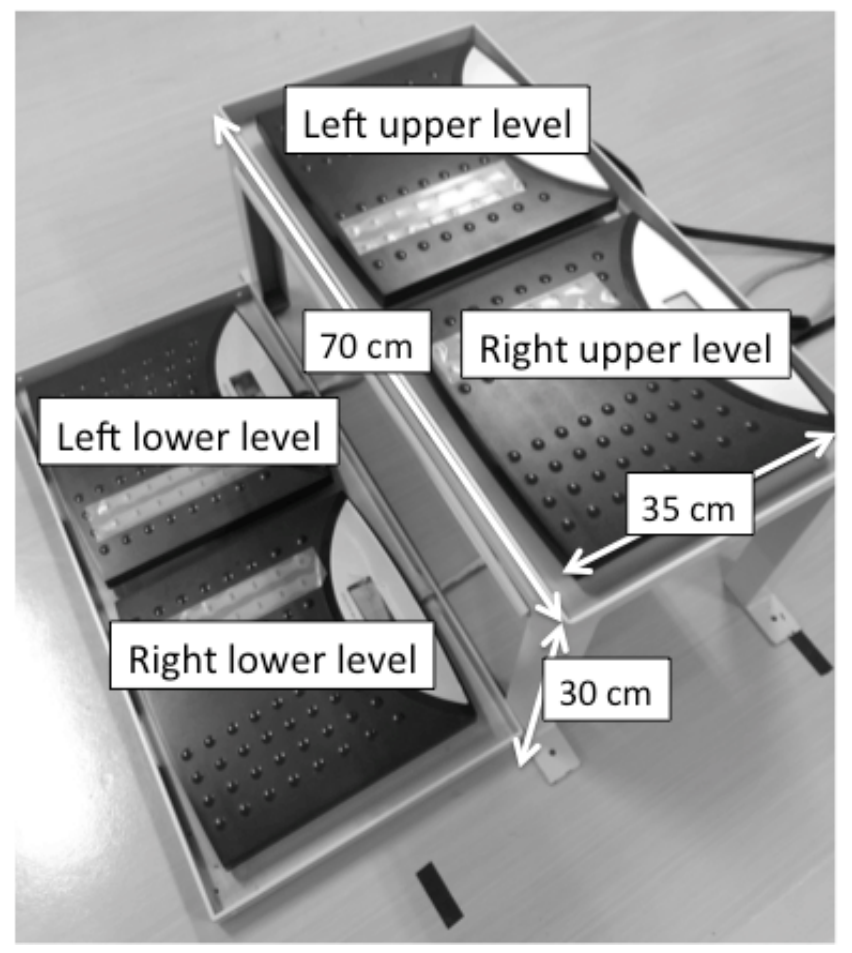

Figure 1

The step up platform used in the present study

Participants stepped up as fast as possible onto the step, starting with the right foot. The starting position was determined as an upright standing position on the lower level with one foot on the left and the other on the right weight scale. The end position was standing with both feet on the upper level, with their feet on each scale.

The load pattern was calculated from a load-time curve to correspond to the parameters that measured the VGRF in the previous study(Bertucco \& Cesari, 2009; Larsen et al., 2008; Reeves, Spanjaard, Mohagheghi, Baltzopoulos, \& 
Maganaris, 2009; Stacoff et al., 2005; Stüssi \& Debrunner, 1980), and the following four parameters were extracted:

1) The maximum load (as a ratio of body weight) during the weight transfer onto the right upper level ( $1^{\text {st }}$ peak load at the right upper level) (Fig 2). 2) The maximum load (as a ratio of body weight) during the push-off phase at the left lower level (last peak load at the left lower level) (Fig 3). 3) The loading rate from the onset of force production to $80 \%$ of the $1^{\text {st }}$ peak load at the right upper level (load slope at the right upper level) (Larsen et al., 2008)(Fig 2).

4) The stepping-up time from when the lower right load is less than $1 \mathrm{~kg}$ until the upper left load reaches above1 $\mathrm{kg}$ (stepping-up time). All data were analyzed using the MATLAB (Version: 8.3, Math Works, USA). 


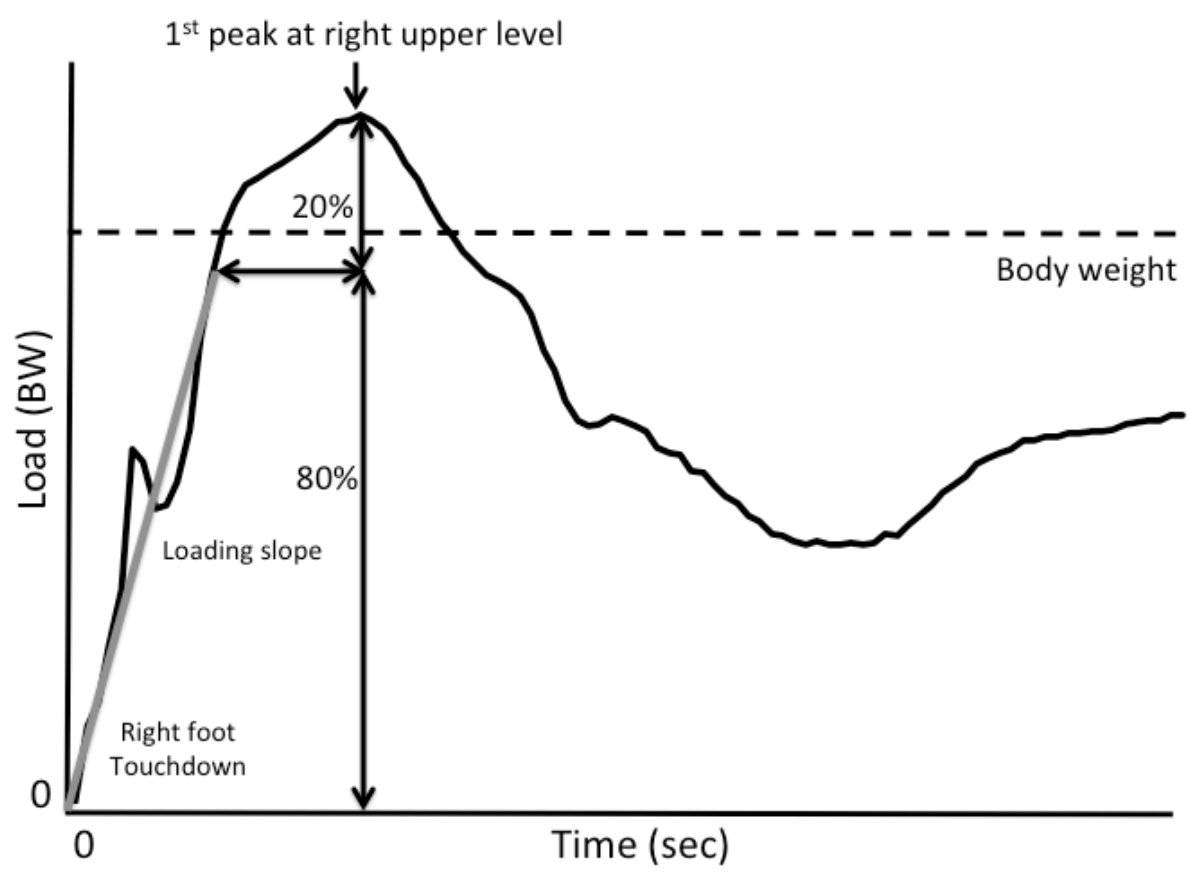

Figure 2

Load-time curve during stepping-up motion at the right upper level

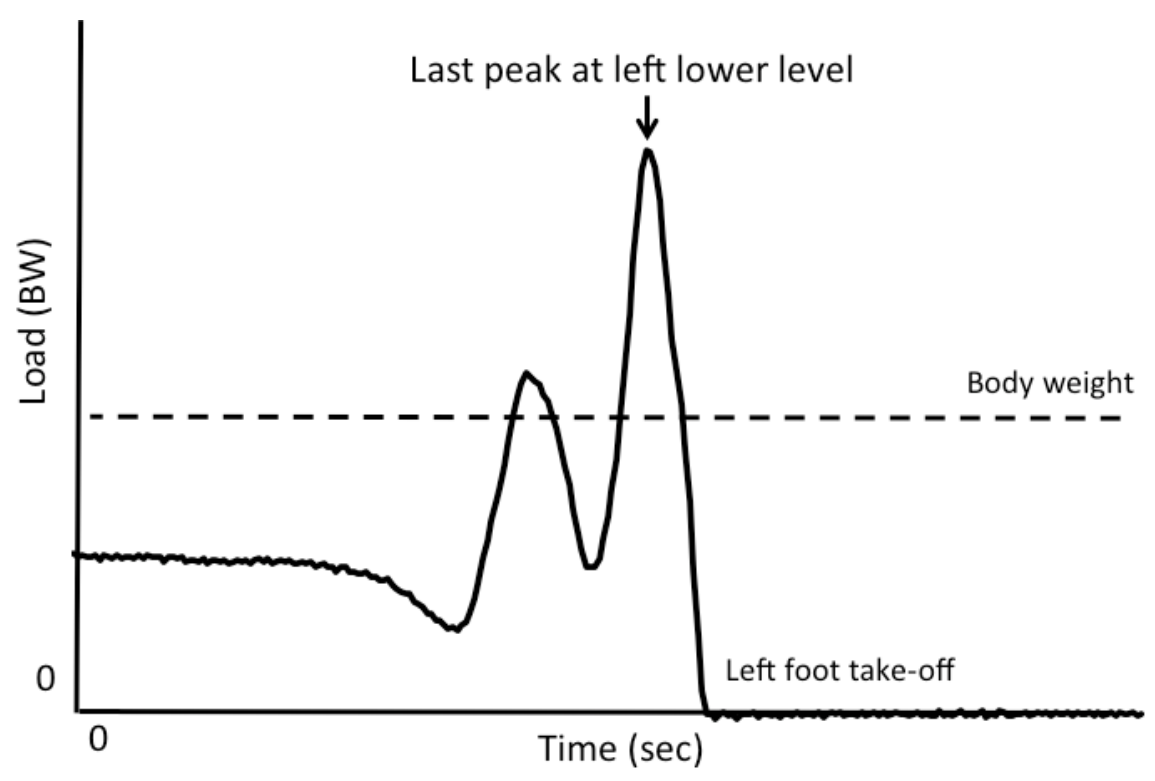

Figure 3

Load-time curve during stepping-up motion at the left lower level 
The test-retest reliability for the measurements of the load patterns was assessed in 39 healthy elderly women (age

$73.5 \pm 8.1$ years).

\subsection{Physical function measurements}

Physical function was assessed in the participants, which included hip and knee extensor strength (an index for muscle strength), the vertical jump test (an index for leg muscle power), the one-legged stance test (OLST) with eyes open (an index for static balance function), the timed "Up \& Go” (TUG) test (an index for dynamic balance function), and the stepping test (an index for lower limb agility).

The hip extensor strength on the right side was measured by a dynamometer (Locomo scan, Allcare, Japan) in a long sitting position at $80^{\circ}$ hip flexion. The knee extensor strength on the right side was measured by a dynamometer (TKK5710e Tension meter, Takei Scientific Instruments, Japan) in a sitting position at $90^{\circ}$ hip and knee flexion. The maximum value from two trials was recorded. The hip and knee extension torque (Nm) was expressed as a percentage of body weight ( $\mathrm{Nm} / \mathrm{kg}$ ). The vertical jump was recorded as the jump height of the highest possible jump of the participants. The maximum value from two trials was used for analysis(Kimura, Mizuta, Yamada, Okayama, \& Nakamura, 2012). The OLST with eyes open was performed with the dominant foot for a maximum time of $180 \mathrm{~s}$. The best time out of two trials was used for analysis(Kimura et al., 2012). The TUG test measured the time that the participant took to stand up from a sitting position in an armless 
chair, walk a distance of $3 \mathrm{~m}$, turn, walk back to the chair, and sit down as fast as possible(Podsiadlo

\& Richardson, 1991). For the stepping test, the participants were seated in a chair with their feet between two lines on the floor, at a $30 \mathrm{~cm}$ interval. The participants were asked to open and close their legs such that their feet would step over the two lines as rapidly as possible. The total number of steps within a $20 \mathrm{~s}$ period was recorded(Kimura et al., 2012).

\subsection{Statistical analyses}

The test-retest reliability for the load pattern was determined using interclass correlation coefficient (ICC) type $(1,1)$ and standard error in measurement (SEM). Pearson's correlation coefficient was used to investigate the relationships between stepping-up time and the loads at the upper and lower levels during the stepping-up motion. A stepwise regression analysis where the dependent variable was load pattern, and independent variables were age and physical function, was performed to determine the association between load pattern during stepping-up motion and physical function in elderly women. All data were analyzed using the PASW Statistics (version 18.0; SPSS Japan, Japan) and level of significance was set at $\mathrm{p}<0.05$.

3. Results

3.1 Reliability for the load pattern during stepping-up motion 
The ICC for the 1st peak load at the right upper level, load slope at the right upper level, last peak load at the left lower level, and stepping-up time were 0.93 [95\% confidence interval (CI), 0.84-0.97. SEM, 0.03], 0.80 [95\% CI, 0.59-0.92. SEM, 0.37], 0.78 [95\% CI, 0.54-0.90. SEM, 0.13], and 0.89 [95\% CI, 0.76-0.95. SEM, 0.15], respectively.

3.2 Correlation between stepping-up time and the loads at the upper and lower levels during the stepping-up motion A correlation analysis among the load patterns revealed that stepping-up time was significantly associated with the last peak load at the left lower level and load slope at the right upper level (Table 1). There was no significant relationship between stepping-up time and 1st peak load at the right upper level (Table 1).

Table 1. Pearson's correlation coefficients ( $r$ ) between stepping-up time and the loads at the upper and lower levels during the stepping-up motion

\begin{tabular}{cccc}
\hline & $\begin{array}{c}1^{\text {st }} \text { peak load at the right } \\
\text { upper level }\end{array}$ & $\begin{array}{c}\text { Last peak load at the left } \\
\text { lower level }\end{array}$ & $\begin{array}{c}\text { Load slope at the right } \\
\text { upper level }\end{array}$ \\
\hline Stepping-up time & 0.03 & $-0.51^{*}$ & $-0.70^{*}$ \\
\hline
\end{tabular}

Values expressed are correlation coefficients.

$* \mathrm{p}<0.05$ was considered as a significant correlation. 
Table 2. Load pattern during stepping-up motion and physical function in the elderly women

\begin{tabular}{lc}
\hline Variables & Means \pm SD \\
\hline
\end{tabular}

Loading pattern

$1^{\text {st }}$ peak load at the right upper level (BW)

$0.96 \pm 0.07$

Last peak load at the left lower level (BW)

$1.32 \pm 0.18$

Load slope at the right top stair tread (BW/s)

$1.83 \pm 0.81$

Stepping up time (s)

$1.04 \pm 0.21$

Physical function

Hip extensor strength $(\mathrm{Nm} / \mathrm{kg})$

$1.75 \pm 0.6$

Knee extensor strength $(\mathrm{Nm} / \mathrm{kg})$

$1.85 \pm 0.5$

Vertical jump test (cm)

$22.36 \pm 6.0$

OLST (s)

$73.28 \pm 68.0$

TUG test (s)

$6.33 \pm 0.9$

Stepping test (steps)

$33.69 \pm 6.0$

BW: Body weight

3.3 Association between load pattern during stepping-up motion and physical function in elderly women

The load pattern during stepping-up motion and the physical function measures in the elderly women were 
summarized in table 2. In the multiple regression analysis for the $1^{\text {st }}$ peak load at the right upper level, only the hip extensor strength was revealed as a significant and independent determinant $(\beta=0.30)$, i.e., peak load at the upper level decreased with a decrease in the hip extensor strength (Table 3). However, the vertical jump test was a significant determinant of the last peak load at the left lower level $(\beta=0.20)$, i.e., the last peak load at the lower level decreased with a decrease in the vertical jump height (Table 4). As for the load slope at the right upper level, the vertical jump and stepping tests were revealed as significant determinants (vertical jump test $\beta=0.22$, stepping test $\beta=0.19$ ) (Table 5). The TUG and stepping tests were significantly associated with stepping-up time (TUG $\beta=0.27$, stepping test $\beta=-0.20$ ) (Table 6).

Table 3. Factors affecting the $1^{\text {st }}$ peak load at the right upper level

\begin{tabular}{lcccccc}
\hline Dependent variable & Independent variable & $\begin{array}{c}\text { Standardized } \\
\text { coefficient }(\beta)\end{array}$ & t value & p value & VIF & $\mathrm{R}^{2}$ \\
\hline $\begin{array}{l}\text { 1st peak load at the } \\
\text { right upper level (BW) }\end{array}$ & Hip extensor strength & 0.30 & 3.20 & $<0.01$ & 1.00 & 0.08 \\
\hline
\end{tabular}

BW: As a ratio of body weight

Table 4. Factors affecting the last peak load at the lower level

\begin{tabular}{llcllll}
\hline Dependent variable & Independent variable & $\begin{array}{c}\text { Standardized } \\
\text { coefficient }(\beta)\end{array}$ & t value & p value & VIF & $\mathrm{R}^{2}$ \\
\hline
\end{tabular}


Last peak load at the

left lower level (BW)

BW: As a ratio of body weight

Table 5. Factors affecting the load slope at the right upper level

\begin{tabular}{lcccccc}
\hline Dependent variable & Independent variable & $\begin{array}{c}\text { Standardized } \\
\text { coefficient }(\beta)\end{array}$ & t value & p value & VIF & $\mathrm{R}^{2}$ \\
\hline $\begin{array}{l}\text { Load slope at the right } \\
\text { upper level (BW/s) }\end{array}$ & Vertical jump test & 0.22 & 2.32 & 0.04 & 1.00 & 0.07 \\
& & & & & \\
& Stepping test & 0.19 & 2.04 & & 1.00 \\
\hline
\end{tabular}

BW: As a ratio of body weight

Table 6. Factors affecting stepping-up time

\begin{tabular}{lcccccc}
\hline Dependent variable & Independent variable & $\begin{array}{c}\text { Standardized } \\
\text { coefficient }(\beta)\end{array}$ & t value & p value & VIF & $\mathrm{R}^{2}$ \\
\hline Stepping up time (s) & TUG & 0.27 & 2.97 & 0.03 & 1.03 & 0.11 \\
& & & & & \\
& Stepping test & -0.20 & -2.16 & & 1.03 \\
\hline
\end{tabular}




\section{Discussion}

The present study revealed that stepping-up time during stepping-up motion at maximum speed was associated

with the last peak load at the lower level, but not with the $1^{\text {st }}$ peak load at the upper level in the elderly women.

These findings suggest that rapid stepping-up ability may be more closely related to the magnitude of push-off at

the lower level rather than the magnitude of the weight acceptance at the upper level after touchdown. A previous

study showed that elderly people who have higher self-reported and objective difficulty in stair ambulation had a longer stair ascent time for 3 steps, and stair ambulation speed was a predictor of functional decline (Oh-Park et al., 2011), that is, the decline in ability to perform stepping-up task quickly was associated with decline in future functional decline in elderly people. Our findings indicated that rapid stepping-up ability in elderly women is more closely related to the maximum load on the lower level than that on the upper level. This finding suggests that the push-off exercise at the lower level may be more effective in improving the ability to step-up as fast as possible, rather than the support exercise at the upper level.

In this study, load patterns such as maximum load and rate of load production during stepping-up motion at maximum speed were measured as indicators of the stepping-up capacity. Additionally, the associations between load patterns during stepping-up motion and physical function were investigated in elderly women. Stepwise regression analyses showed that hip extensor strength and scores on the vertical jump, TUG, and stepping tests were associated with the load pattern during the stepping-up motion. This suggests that among physical function, hip 
extensor strength, leg muscle power, dynamic balance function, and agility influence the stepping-up capacity in elderly women.

Our results showed that the $1^{\text {st }}$ peak load at the upper level was associated with hip extensor strength, but not with knee extensor strength. Previous studies that measured the maximal step-up height(Nyberg et al., 2011) and time to ascent 8 steps(Samuel et al., 2011) reported that these capacities were associated with knee extensor strength. A previous study on hip and knee joint moments during the stepping-up motion reported that the peak extension moment at the knee joint was greater than peak extension at the hip joint(Protopapadaki, Drechsler, Cramp, Coutts, \& Scott, 2007), while another study reported that peak extension moment at the hip joint was greater than the peak extension at the knee joint(Bertucco \& Cesari, 2009). However, no study has investigated whether the hip extensor strength is associated with stepping-up capacity in elderly people. The results of the present study suggest that hip extensor strength may be more closely related to stepping-up capacity in elderly people than is knee extensor strength.

The last peak load at the lower level and load slope at the upper level were found to be associated with leg muscle power in the present study. Previous studies demonstrated that stair ascent of 10 steps, as fast as possible, was associated with leg muscle power in elderly people(Bean et al., 2007) and that performance of stair ascent required more leg joint power with increasing staircase inclination(Riener, Rabuffetti, \& Frigo, 2002). The stair inclination angle used in the current study was $40.6^{\circ}$, which is relatively steep. Therefore, greater muscle power may be 
necessary when elderly women performed the stepping-up as fast as possible.

The stepping-up time was significantly associated with TUG, which was used as an index of dynamic balance function in the current study. As for the association between balance function and stepping-up speed, postural sway, i.e., static balance function, was associated with stepping-up speed(Tiedemann, Sherrington, \& Lord, 2007). However, no previous studies have examined whether balance function, including dynamic balance function, is associated with stepping-up speed in elderly people. The results of this study suggest that stepping-up speed may be more strongly influenced by dynamic balance function, which is measured by the TUG test, in elderly people than is the static balance function measured by the OLST.

Furthermore, the load slope at the upper level and stepping-up time were associated with agility, which was measured by the stepping test. Greater loss of type II muscle fibers(Lexell, 1995) and higher antagonist muscle coactivation(Macaluso et al., 2002) with aging may contribute to the age-related decline of agility. In fact, it has been reported that high antagonist muscle coactivation is observed during stair ambulation in elderly people(Larsen et al., 2008). In this context, the results of this study suggested that lower limb agility has an important role in performing stepping-up quickly in elderly people.

The results of the present study suggest that rapid stepping-up ability among elderly women may be more closely related to the maximum load during push-off at the lower level rather than that during weight loading on the upper level. In addition, our findings showed that the ability to perform stepping-up quickly required various 
physical functions such as hip extensor strength, leg muscle power, dynamic balance function, and agility. These findings suggest that interventions considering the multidimensional factor across various aspects of physical function may be required for improving or maintaining stepping-up capacity in elderly women.

The present study has several limitations. First, our measurements of physical function did not include aspects regarding neuromuscular coordination and proprioception. Moreover, we measured the load pattern during steppingup motion using a $30 \mathrm{~cm}$ step, which is quite high, since the participants in this study had a high level of physical function. Actually, the value of TUG tests in our study $(6.33 \pm 0.9 \mathrm{~s})$ was lower compared to the reference value among community-dwelling older adults (8.54 \pm 0.2 s)(Isles, Low Choy, Steer, \& Nitz, 2004). Further studies are needed to investigate the association between load patterns and physical function including aspects such as neuromuscular coordination in frail elderly, who are most likely to exhibit disability in stair ambulation.

\section{Conclusions}

We investigated the relationships between the load pattern during stepping-up motion at maximum speed and physical function in elderly women. Our results showed that stepping-up time was significantly related to the last peak load at the lower level. However, there was no significant relationship between the $1^{\text {st }}$ peak load at the upper level and stepping-up time. Furthermore, we found that the load pattern during stepping-up motion among elderly women is closely related with various physical functions such as the hip extensor strength, leg muscle power, 
dynamic balance function, and agility.

\section{Conflict of interest statement}

The authors have no conflict of interest. 


\section{Acknowledgement}

Kyoritsu Denshi Kogyo Co. Ltd financed this study. The financial providers did not contribute to the implementation of the study, analysis, or interpretation of the data, or preparation of this article. 
References

Bean, J. F., Kiely, D. K., LaRose, S., Alian, J., \& Frontera, W. R. (2007). Is Stair Climb Power a Clinically Relevant Measure of Leg Power Impairments in At-Risk Older Adults? Archives of Physical Medicine and Rehabilitation, 88(May), 604-609. doi:10.1016/j.apmr.2007.02.004

Bertucco, M., \& Cesari, P. (2009). Dimensional analysis and ground reaction forces for stair climbing: effects of age and task difficulty. Gait \& Posture, 29, 326-331.

doi:10.1016/j.gaitpost.2008.10.052

Gill, T. M., \& Kurland, B. (2003). The burden and patterns of disability in activities of daily living among community-living older persons. The Journals of Gerontology. Series A, Biological Sciences and Medical Sciences, 58(1), 70-75. doi:10.1093/gerona/58.1.M70

Hortobagyi, T., Mizelle, C., Beam, S., \& DeVita, P. (2003). Old adults perform activities of daily living near their maximal capabilities. The Journals of Gerontology. Series A, Biological Sciences and Medical Sciences, 58(5), M453-M460. doi:10.1093/gerona/58.5.M453

Isles, R. C., Low Choy, N. L., Steer, M., \& Nitz, J. C. (2004). Normal values of balance tests in women aged 20-80. Journal of the American Geriatrics Society, 52(8), 1367-1372. doi:10.1111/j.1532-5415.2004.52370.x

Kimura, M., Mizuta, C., Yamada, Y., Okayama, Y., \& Nakamura, E. (2012). Constructing an index 
of physical fitness age for Japanese elderly based on 7-year longitudinal data: Sex differences in estimated physical fitness age. Age, 34(1), 203-214. doi:10.1007/s11357-011-9225-5

Larsen, A. H., Puggaard, L., Hamalainen, U., \& Aagaard, P. (2008). Comparison of ground reaction forces and antagonist muscle coactivation during stair walking with ageing. Journal of Electromyography and Kinesiology: Official Journal of the International Society of Electrophysiological Kinesiology, 18(4), 568-80. doi:10.1016/j.jelekin.2006.12.008

Lexell, J. (1995). Human aging, muscle mass, and fiber type composition. The Journals of Gerontology. Series A, Biological Sciences and Medical Sciences, 50 Spec No(10), 11-6. doi:10.1093/gerona/50A.Special_Issue.11

Lin, H.-C., Hsu, H.-C., Chang, C.-M., Chiou, P.-W., \& Lu, T.-W. (2010). Alterations of kinetic characteristics in step up and over test in patients with anterior cruciate ligament deficiency. Journal of Sports Science \& Medicine, 9(3), 472-9. Retrieved from http://www.pubmedcentral.nih.gov/articlerender.fcgi?artid=3761710\&tool=pmcentrez\&rendert ype=abstract

Macaluso, A., Nimmo, M. A., Foster, J. E., Cockburn, M., McMillan, N. C., \& De Vito, G. (2002). Contractile muscle volume and agonist-antagonist coactivation account for differences in torque between young and older women. Muscle and Nerve, 25(6), 858-863. doi:10.1002/mus.10113 
Mattacola, C. G., Jacobs, C. A., Rund, M. A., \& Johnson, D. L. (2004). Functional assessment using the step-up-and-over test and forward lunge following ACL reconstruction. Orthopedics, 27(6), 602-608. doi:10.1097/00005768-200205001-00552

Michel-Pellegrino, V., Hewson, D., Hogrel, J. Y., \& Duchene, J. (2008). Biomechanical analysis of older adults stepping up: A method of evaluating balance. Journal of Aging and Physical Activity, 16(2), 171-187.

Novak, A. C., \& Brouwer, B. (2011). Sagittal and frontal lower limb joint moments during stair ascent and descent in young and older adults. Gait \& Posture, 33(1), 54-60. doi:10.1016/j.gaitpost.2010.09.024

Novak, A. C., Li, Q., Yang, S., \& Brouwer, B. (2011). Mechanical energy transfers across lower limb segments during stair ascent and descent in young and healthy older adults. Gait \& Posture, 34(3), 384-390. doi:10.1016/j.gaitpost.2011.06.007

Nyberg, L. A., Hellenius, M. L., Kowalski, J., Wandell, P., Andersson, P., \& Sundberg, C. J. (2011). Repeatability and validity of a standardised maximal step-up test for leg function-a diagnostic accuracy study. BMC Musculoskeletal Disorders, 12(1), 191. doi:10.1186/1471-2474-12-191

Oh-Park, M., Wang, C., \& Verghese, J. (2011). Stair negotiation time in community-dwelling older adults: Normative values and association with functional decline. Archives of Physical 
Medicine and Rehabilitation, 92(12), 2006-2011. doi:10.1016/j.apmr.2011.07.193

Podsiadlo, D., \& Richardson, S. (1991). The timed “Up \& Go”: a test of basic functional mobility for frail elderly persons. Journal of the American Geriatrics Society, 39(2), 142-8. Retrieved from http://www.ncbi.nlm.nih.gov/pubmed/1991946

Pozzi, F., Snyder-Mackler, L., \& Zeni, J., J. (2015). Relationship between biomechanical asymmetries during a step up and over task and stair climbing after total knee arthroplasty. Clinical Biomechanics, 30(1), 78-85. doi:10.1016/j.clinbiomech.2014.11.001

Protopapadaki, A., Drechsler, W. I., Cramp, M. C., Coutts, F. J., \& Scott, O. M. (2007). Hip , knee , ankle kinematics and kinetics during stair ascent and descent in healthy young individuals, 22, 203-210. doi:10.1016/j.clinbiomech.2006.09.010

Reeves, N. D., Spanjaard, M., Mohagheghi, A. A., Baltzopoulos, V., \& Maganaris, C. N. (2009). Older adults employ alternative strategies to operate within their maximum capabilities when ascending stairs. Journal of Electromyography and Kinesiology, 19(2), e57-e68. doi:10.1016/j.jelekin.2007.09.009

Riener, R., Rabuffetti, M., \& Frigo, C. (2002). Stair ascent and descent at different inclinations. Gait and Posture, 15, 32-44. doi:10.1016/S0966-6362(01)00162-X

Samuel, D., Rowe, P., Hood, V., \& Nicol, A. (2011). The biomechanical functional demand placed 
on knee and hip muscles of older adults during stair ascent and descent. Gait and Posture,

34(2), 239-244. doi:10.1016/j.gaitpost.2011.05.005

Stacoff, A., Diezi, C., Luder, G., Stussi, E., \& Kramers-de Quervain, I. A. (2005). Ground reaction forces on stairs: Effects of stair inclination and age. Gait and Posture, 21, 24-38. doi:10.1016/j.gaitpost.2003.11.003

Startzell, J. K., Owens, D. a, Mulfinger, L. M., \& Cavanagh, P. R. (2000). Stair negotiation in older people: a review. Journal of the American Geriatrics Society.

Stüssi, E., \& Debrunner, H. U. (1980). Parameter-Analyse des menschlichen Ganges.

Biomedizinische Technik/Biomedical Engineering. doi:10.1515/bmte.1980.25.s1.222

Tiedemann, A. C., Sherrington, C., \& Lord, S. R. (2007). Physical and psychological factors associated with stair negotiation performance in older people. The Journals of Gerontology. Series A, Biological Sciences and Medical Sciences, 62(11), 1259-1265. doi:10.1093/gerona/62.11.1259

van Iersel, M. B., Olde Rikkert, M. G., \& Mulley, G. P. (2003). Is stair negotiation measured appropriately in functional assessment scales? Clinical Rehabilitation, 17, 325-333. doi:10.1191/0269215502cr628oa

Verghese, J., Wang, C., Xue, X., \& Holtzer, R. (2008). Self-Reported Difficulty in Climbing Up or 
Down Stairs in Nondisabled Elderly. Archives of Physical Medicine and Rehabilitation,

89(January), 100-104. doi:10.1016/j.apmr.2007.08.129 